\title{
A time motion study in the OPD clinic of a rural hospital of West Bengal
}

\author{
Dr Nirmalya Manna ${ }^{1}$,Dr Md Samsuzzaman ${ }^{1}$,Dr Saikat Das ${ }^{1}$ \\ ${ }^{1}$ Department of Community Medicine, Medical College Kolkata
}

\begin{abstract}
A time motion study was conducted to know the time taken in different service delivery points in outpatient department and to assess the perception of beneficiaries regarding the total time spent in the OPD. The study was conducted at Tarakeswar rural hospital from January to April 2014. About 192 patients were included in the study. According to $46.88 \%$ population, total time was too long. $42.70 \%$ population were not satisfied about the total time taken in the OPD. $29.16 \%$ population had given the suggestion. $42.86 \%$ of the population (who had given any suggestion) suggested appointing more doctors. Much more in-depth research work on Time Motion study is required for proper time management in different health care delivery system and subsequent remedial steps can be taken accordingly.
\end{abstract}

Key words: Time motion study, OPD, patient satisfaction, rural hospital

\section{Introduction}

Time is one of the most valuable things to us. A time and motion study (or time-motion study) is a business efficiency technique combining the time study work of Frederick Winslow Taylor (1881 A.D) with the motion study work of Frank B. Gilberth and his wife Lillian Gilbreth (1885A.D). It is a major part of scientific management (Taylorism) ${ }^{1}$. Motion study is designed to determine best way to complete a repetitive job while the time study measures how long it takes an average worker to complete a task at a normal pace. Historically the two studies are discussed individually; today they generally are discussed as one. The two techniques became integrated and refined into a widely accepted method applicable to the improvement and upgrading of work systems. This integrated approach to work system improvement is applied to determine schedules and planning of work in industrial as well as service organizations, including banks, schools and hospitals ${ }^{2}$. The objective of the Time and Motion Study is to determine a 'normal' or average time for a job, by using observers to record exactly how much time is being devoted to each task. With this objective, time and motion studies can be effective for performance evaluations as well as can be used for planning purposes $\mathbf{s}^{3,4}$. During the last decade, the number of patients seeking Outpatient Department (OPD) services has increased many folds, but the facilities in the OPD have not increased at the same rate. Huge number of patients in the OPDs with limited manpower, especially in Rural Hospital, creates chaos as well as the chance of mismanagement. OPD thus requires a systematic study of its service for its efficient management and function. It is therefore imperative that a simple time and motion study of an OPD system and suitable inexpensive interventions can go a long way to improve the efficiency of a hospital. Dearth of literature has been found on time and motion study in OPD settings with OPD of rural hospital as rarity. Hence the present study was carried out in the OPD clinic of a rural hospital to know the time taken in different service delivery points in outpatient department and to assess the perception of beneficiaries regarding the total time spent in the OPD.

\section{Methodology}

It was an observational descriptive study with institution based cross sectional design carried out in Tarakeswar rural hospital (field practice area of Medical College, Kolkata), district - Hooghly, West Bengal. Total study period was four month (January to April, 2014) out of which data collection period was two months. From the available record of last one year from Tarakeswar rural hospital it has been found that average number of patient attending OPD per day is 100, approximately 50 attending general OPD \& 50 attending Maternal and Child Health OPD. With the pre testing it has been found that every day 12 proforma can be filled up. Going twice a week (Monday and Wednesday) for two month yields 17 working days. Therefore expected sample size was 204. But taking non respondents into consideration, ultimate sample size was 192. As the patient attending general OPD \& MCH OPD was 1:1, therefore approximately 6 patient from general OPD ( every $8^{\text {th }}$ patient $) \&$ 6 patient from MCH OPD (every $8^{\text {th }}$ patient) was taken into consideration. They were taken alternatively. Token cum paper, Pre-designed pre-tested schedule, Wrist watch and clip board were used as a tools. Consent from $\mathrm{BMOH}$ was taken. A table was arranged at the entrance of patient and times were calibrated in all OPD table \& pathological/radiological centre. In all the OPD tables including pathological/radiological centres, it was informed to the concerned person to note down the time after end of the procedure. As the patient enters the rural hospital, a token cum paper with the names of all the tables was supplied. They were requested to come to 
the entrance table after the completion of all the procedures. Exit time was noted and socio demographic data was collected during the exit of the patient. Data was compiled and analysed by appropriate statistical method (SPSS 20.0 etc). Time was noted at the entrance ( Table 0), After completion of registration (Table 1), After completion of medical check up ( Table 2), After completion of taking medicine slip (Table 3), After completion of taking medicine (Table 4), After completion of any pathological test\&/or any radiological test ( Table 5), Exit time (Table 0). Those who are above 18 years old, those who have given consent, those who are not seriously ill, those completed at least up to taking medicine (i.e., up to Table 4) were included in the study.

\section{Results}

Most of the study population (47.92\%) belongs to $25-34$ years age group. $60.42 \%$ of populations are female. Mean age (in years) was $32.04 \pm 11.639$. Maximum percentage $(41.67 \%$ ) of study population belonged to class IV (lower middle) followed by class v (poor) social class (according to modified Prasad's scale; adjusted to price index March'2013). Most of the study population (37.50\%) completed primary education. Among those who is coming for MCH services, maximum percentages (54.19\%) of study population received ANC services. 54.2\% attending OPD are follow up cases and rest are new cases. Mean time is maximum (18.54 min) in registration to check up table. $56.25 \%$ population attend OPD before 12 noon. 66.67\% population (among the study population who required any lab investigations) required only pathological tests. Mean time taken is maximum (44 $\mathrm{min}$ ) for both pathological \& radiological investigations. Mean total time (entrance to exit) is maximum (106 $\mathrm{min}$ ) for those required any laboratory investigations. Mean times in table -1 were lower (17.19 $\mathrm{min})$ in old or follow up cases than that of new cases $(20.50 \mathrm{~min})$. Total mean time was higher in new cases (79.68 min). Mean time was higher in MCH cases in Table -2 \& entrance to exit. In Monday, Mean time was greater in all tables including mean total time between entrances to exit. Mean time was higher in all tables for those who have entrance time before 12 noon. According to $46.88 \%$ population, total time was too long. $42.70 \%$ population were not satisfied about the total time taken in the OPD while $30.21 \%$ population were satisfied regarding the total time. $29.16 \%$ population had given the suggestion. $42.86 \%$ of the population (who had given any suggestion) suggested appointing more doctors.

\section{Discussion}

Historically time motion studies were used in the manufacturing industry to evolve pay scales with the thought that money was the only motivation for the work. Today, time motion study can be effective for performance evaluation, for planning purposes in order to predict the level of output that may be achieved and can be used to unmask problems and create solutions and also can be used for time cost analysis. The outpatient department is the point of contact between the health care facility and the community. The problems of OPDs of developing countries are long waiting times, long queues, inefficient staffs, absence of staffs etc. The problem is graver when the OPD runs in the rural area, because of huge patient load. No comparable time motion studies have been carried out in any other OPD of rural hospital. But other time motion studies have been carried out in relation to immunization clinic, surgical interventions, nursing activity monitoring. The salient features of the study were mean time in table $1,2,3,4$ is $18.71,18.54,14.83,13.73$ minutes respectively with S.D 6.531, 6.042, $5.666,6.546$ minutes respectively. Mean time is maximum in table 1 probably due to double kind of services in table 1 viz., registration and generation of medicine slip. Mean time in table -1 is higher (20.50 minutes) in new cases than that of old cases (17.19 minutes); probably due to writing of detailing of the patient. Mean time is higher in MCH cases (19.17 minutes) in comparison to other patients (17.92 $\mathrm{min}$ ) in Table - 2; probably due to examination of ANC mothers. This time also reflects the total time (entrance to exit); 78.12 minutes for $\mathrm{MCH}$ care while $74.58 \mathrm{~min}$ for other patients. In comparison to Wednesday, mean time is greater in Monday in all tables including mean total time between entrance to exit; probably due to more patient rush in Monday in comparison to Wednesday. Mean time is higher in all tables for those who have entrance time before 12 noon suggesting patient rush is more before 12 noon. Despite of some identified problems like rush of patients in Monday in comparison to Wednesday or rush of patients before 12 Noon, they may have some relations to other factors like number of staffs present on the particular day of study or the efficiency of the involved staffs on that day. However these factors need to be studied further \& of course in depth. The quality of service delivery in the OPD setting in rural areas can be improved if the problems in the system is identified, properly analyzed and attempts are made to overcome them. Perhaps this study will help in the initiation of further in-depth analysis. Based upon the result and of course keeping in mind the suggestions given by the responded, following are some recommendations: Either more doctors or efficient doctors will decrease time in table- 2 . The best would be combination of the two. At the registration counter, double functioning is carried on. Therefore time taken for either registration or generation of medicine slip becomes longer. Better would have been separate counter. Separate counter for old and new patient may reduce some time load. 


\section{Conclusion}

Efficient functioning and smooth running of any OPDs requires a very good time management. The study aimed to initiate an effort to study the utilization of time at the OPD setting, Much more in-depth research work on Time Motion study is required for proper time management in different health care delivery system and subsequent remedial steps can be taken accordingly.

\section{References}

[1]. Chattopadhyay A, Ghosh R, Maji S, Ray TG, Lahiri SK. Atime motion study in the immunization clinic of a tertiary care hospital of Kolkata, West Bengal. Indian J Community Med 2012; 37(1): 30-3

[2]. Gowler D and Legge K. Writing and the Advent of Scientific Management: The Case of Time and Motion Studies. Scandinavian Journal of Management[Internet]. [Cited on 2013, Dec 10 $0^{\text {th }}$ ]. 12(1): 41-55

[3]. Baumgart A. Neuhauser D. Frank and Lillian Gilbreth: Scientific Management in the Operating Room. Quality Safety Health Care. [Internet] [cited on 2013, Dec 12 ${ }^{\text {th }}$ ] 2009. 18(2); 413-415

[4]. John N. Murthy GV. Vashisht P. Gupta SK. Work capacity and surgical output for cataract in the national capital region of Delhi and neighbouring districts of North India. [ Internet]. Indian J Public Health. 2008. 52(3);177-84

Tables and Charts

Table 1: Analysis of service delivery time at different tables $(\mathrm{n}=192)$

(All time was calculated in minute)

\begin{tabular}{|l|c|c|c|}
\hline Table No & Mean & SD & Range \\
\hline 0 to1 & 18.17 & 6.531 & 28 \\
\hline 1 to 2 & 18.54 & 6.042 & 24 \\
\hline 2 to 3 & 14.83 & 5.666 & 28 \\
\hline 3 to 4 & 13.73 & 6.546 & 25 \\
\hline
\end{tabular}

Table 2: Comparison of time taken in different table between new and old cases (For new cases, $\mathrm{n}=88$ and for old cases, $\mathrm{n}=104$ )

(All time in minutes)

\begin{tabular}{|c|c|c|c|}
\hline Table & Case & Mean & SD \\
\hline \multirow[t]{2}{*}{0 to 1} & New & 20.50 & 7.642 \\
\hline & Old & 17.19 & 5.010 \\
\hline \multirow[t]{2}{*}{1 to 2} & New & 18.23 & 7.139 \\
\hline & Old & 18.81 & 4.986 \\
\hline \multirow[t]{2}{*}{2 to 3} & New & 16.09 & 7.364 \\
\hline & Old & 13.77 & 3.399 \\
\hline \multirow[t]{2}{*}{3 to 4} & New & 13.45 & 6.410 \\
\hline & Old & 13.96 & 6.712 \\
\hline \multirow{2}{*}{ Entrance to Exit } & New & 79.68 & 31.068 \\
\hline & Old & 70.54 & 26.017 \\
\hline
\end{tabular}

Table 3: Comparison of time taken in different table between $\mathrm{MCH}$ and other services (For MCH services, $\mathrm{n}=96$ and for other services, $\mathrm{n}=96$ )

(All time in minutes)

\begin{tabular}{|l|c|c|c|}
\hline Table & Services & Mean & SD \\
\hline \multirow{2}{*}{0 to 1} & MCH & 18.67 & 7.216 \\
\hline \multirow{2}{*}{1 to 2} & Other & 18.75 & 4.681 \\
\cline { 2 - 4 } & MCH & 19.17 & 7.019 \\
\cline { 2 - 4 } 2 to 3 & Other & 17.92 & 6.817 \\
\cline { 2 - 4 } & MCH & 14.96 & 7.296 \\
\hline \multirow{2}{*}{3 to 4} & Other & 14.98 & 6.817 \\
\cline { 2 - 4 } & MCH & 14.50 & 6.240 \\
\hline \multirow{2}{*}{ Entrance to Exit } & Other & 78.12 & 26.313 \\
\cline { 2 - 4 } & MCH & 74.58 & 31.106 \\
\hline
\end{tabular}

Table 4: Comparison of time taken in different table with respect to day of visit (Mean time in minutes)

\begin{tabular}{|l|c|c|c|c|c|}
\hline Days & Table 0 to 1 & Table 1 to 2 & Table 2 to 3 & Table 3 to 4 & $\begin{array}{c}\text { Entrance to exit } \\
\text { (min) }\end{array}$ \\
\hline $\begin{array}{l}\text { Monday } \\
(\mathrm{n}=96)\end{array}$ & 19.20 & 17.45 & 14.66 & 13.83 & 75 \\
\hline $\begin{array}{l}\text { Wednesday } \\
(\mathrm{n}=96)\end{array}$ & 17.20 & 17.02 & 14 & 13.62 & 74.45 \\
\hline
\end{tabular}


Table 5: Distribution of study population according to perception regarding the total time taken in the OPD and level of satisfaction $(n=192)$

\begin{tabular}{|c|c|c|c|c|c|c|}
\hline \multirow[t]{2}{*}{ Responses } & \multirow[t]{2}{*}{ Number } & \multirow[t]{2}{*}{$\begin{array}{l}\text { Percentage of } \\
\text { total }\end{array}$} & \multicolumn{4}{|c|}{$\begin{array}{c}\text { Level of satisfaction } \\
\text { ( number with percentages with respect to the } \\
\text { responses) }\end{array}$} \\
\hline & & & Not satisfied & Avg. Satisfied & Satisfied & $\begin{array}{l}\text { Don't know / } \\
\text { can't say }\end{array}$ \\
\hline Too long & 90 & 46.88 & $\begin{array}{c}68 \\
(75.56 \%) \\
\end{array}$ & $\begin{array}{c}8 \\
(8.89 \%) \\
\end{array}$ & $\begin{array}{c}4 \\
(4.44 \%) \\
\end{array}$ & $\begin{array}{c}10 \\
(11.11 \%)\end{array}$ \\
\hline As per need & 60 & 31.25 & $\begin{array}{c}2 \\
(3.33 \%)\end{array}$ & $\begin{array}{c}10 \\
(16.67 \%)\end{array}$ & $\begin{array}{c}38 \\
(63.33 \%)\end{array}$ & $\begin{array}{c}10 \\
(16.67 \%)\end{array}$ \\
\hline Too short & 16 & 8.33 & $\begin{array}{c}0 \\
(0.00 \%) \\
\end{array}$ & $\begin{array}{c}6 \\
(37.50 \%) \\
\end{array}$ & $\begin{array}{c}10 \\
(62.50 \%) \\
\end{array}$ & $\begin{array}{c}0 \\
(0.00 \%) \\
\end{array}$ \\
\hline Can't say & 26 & 13.54 & $\begin{array}{c}12 \\
(46.15 \%) \\
\end{array}$ & $\begin{array}{c}4 \\
(15.39 \%) \\
\end{array}$ & $\begin{array}{c}6 \\
(23.08 \%) \\
\end{array}$ & $\begin{array}{c}4 \\
(15.38 \%) \\
\end{array}$ \\
\hline Total & 192 & 100 & $\begin{array}{c}82 \\
(42.70 \%)\end{array}$ & $\begin{array}{c}28 \\
(14.58 \%)\end{array}$ & $\begin{array}{c}58 \\
(30.21 \%)\end{array}$ & $\begin{array}{c}24 \\
(12.51 \%)\end{array}$ \\
\hline
\end{tabular}

